\title{
Bardoxolone Methyl Improves Kidney Function in Patients with Chronic Kidney Disease Stage 4 and Type 2 Diabetes: Post-Hoc Analyses from Bardoxolone Methyl Evaluation in Patients with Chronic Kidney Disease and Type 2 Diabetes Study
}

\author{
Melanie P. Chin ${ }^{a}$ George L. Bakris ${ }^{b}$ Geoffrey A. Block ${ }^{c}$ Glenn M. Chertow ${ }^{d}$ \\ Angie Goldsberry ${ }^{a}$ Lesley A. Inker ${ }^{e}$ Hiddo J.L. Heerspink ${ }^{f}$ Megan O'Grady $^{a}$ \\ Pablo E. Pergolag Christoph Wanner ${ }^{\mathrm{h}}$ David G. Warnock ${ }^{\mathrm{i}} \quad$ Colin J. Meyer $^{\mathrm{a}}$ \\ ${ }^{a}$ Reata Pharmaceuticals, Irving, TX, USA; ${ }^{b}$ University of Chicago Medicine, Chicago, IL, USA; 'Denver Nephrology,

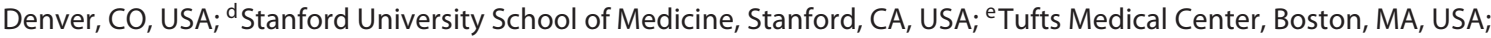 \\ fDepartment of Clinical Pharmacy and Pharmacology University of Groningen, University Medical Center Groningen,

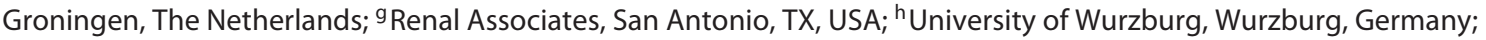 \\ 'University of Alabama at Birmingham, Birmingham, AL, USA
}

\section{Keywords}

Bardoxolone methyl · eGFR

\begin{abstract}
Background: Increases in measured inulin clearance, measured creatinine clearance, and estimated glomerular filtration rate (eGFR) have been observed with bardoxolone methyl in 7 studies enrolling approximately 2,600 patients with type 2 diabetes (T2D) and chronic kidney disease (CKD). The largest of these studies was Bardoxolone Methyl Evaluation in Patients with Chronic Kidney Disease and Type 2 Diabetes (BEACON), a multinational, randomized, double-blind, placebo-controlled phase 3 trial which enrolled patients with T2D and CKD stage 4. The BEACON trial was terminated after preliminary analyses showed that patients randomized to bardoxolone methyl experienced significantly higher rates of heart failure events. We performed post-hoc analyses to characterize changes in kidney func-
\end{abstract}

tion induced by bardoxolone methyl. Methods: Patients in BEACON $(n=2,185)$ were randomized 1:1 to receive oncedaily bardoxolone methyl $(20 \mathrm{mg}$ ) or placebo. We compared the effects of bardoxolone methyl and placebo on a post-hoc composite renal endpoint consisting of $\geq 30 \%$ decline from baseline in eGFR, eGFR $<15 \mathrm{~mL} / \mathrm{min} / 1.73 \mathrm{~m}^{2}$, and end-stage renal disease (ESRD) events (provision of dialysis or kidney transplantation). Results: Consistent with prior studies, patients randomized to bardoxolone methyl experienced mean increases in eGFR that were sustained through study week 48. Moreover, increases in eGFR from baseline were sustained 4 weeks after cessation of treatment. Patients randomized to bardoxolone methyl were significantly less likely to experience the composite renal endpoint (hazards ratio 0.48 [95\% Cl 0.36-0.64]; $p<0.0001$ ). Conclusions: Bardoxolone methyl preserves kidney function and may delay the onset of ESRD in patients with $T 2 D$ and stage 4 CKD.

(c) 2018 The Author(s) Published by S. Karger AG, Basel

\begin{tabular}{ll}
\hline KARGER & $\begin{array}{l}\text { @ 2018 The Author(s) } \\
\text { Published by S. Karger AG, Basel Openger }\end{array}$ \\
E-Mail karger@karger.com & This article is licensed under the Creative Commons Attribution- \\
www.karger.com/ajn & $\begin{array}{l}\text { NonCommercial-NoDerivatives 4.0 International License (CC BY- } \\
\text { NC-ND) (http://www.karger.com/Services/OpenAccessLicense). } \\
\text { Usage and distribution for commercial purposes as well as any dis- } \\
\text { tribution of modified material requires written permission. }\end{array}$
\end{tabular}

Colin J. Meyer

Reata Pharmaceuticals

2801 Gateway Drive, Suite 150

Irving, TX 75063 (USA)

E-Mail colin.meyer@ reatapharma.com 


\section{Introduction}

Through activation of Nrf2 (nuclear factor erythroidderived 2-related factor 2) and inhibition of NF- $\mathrm{KB}$ (nuclear factor kappa-light-chain-enhancer of activated Bcells), bardoxolone methyl, a semi-synthetic triterpenoid, upregulates the antioxidant response and suppresses proinflammatory signaling to reduce oxidative stress and inflammation and promote mitochondrial function $[1,2]$. Bardoxolone methyl and close analogs demonstrate efficacy in multiple rodent models of kidney disease, including chronic kidney disease (CKD) induced by 5/6 nephrectomy [3], cisplatin-induced acute nephrotoxicity $[4,5]$, angiotensin II-induced kidney injury [6], and protein overload-induced nephropathy [7]. Bardoxolone methyl has also been studied in 7 clinical trials enrolling approximately 2,600 patients with type 2 diabetes (T2D) and CKD. Improvements in glomerular filtration rate (GFR), assessed using measured inulin clearance, measured creatinine clearance, and estimated GFR (eGFR), have been observed with bardoxolone methyl treatment in a number of clinical trials [8-11]. The largest of these was a multinational, randomized, double-blind, placebocontrolled phase 3 outcomes trial, which enrolled 2,185 patients with T2D and CKD stage 4 (Bardoxolone Methyl Evaluation in Patients with Chronic Kidney Disease and Type 2 Diabetes [BEACON]: The Occurrence of Renal Events study) [10].

The BEACON trial was terminated for safety concerns in response to a recommendation from the independent data monitoring committee, which identified a significant increase in the risk of heart failure hospitalizations or death from heart failure with bardoxolone methyl treatment (96 [8.8\%] patients randomized to bardoxolone methyl versus 55 [5.0\%] patients randomized to placebo) [10]. After BEACON was terminated, analyses suggested that the primary reason for the increase in adjudicated heart failure related outcomes in the treatment group was not direct toxicity, but fluid overload, which occurred in the first 4 weeks after randomization [12]. Post-hoc analysis from BEACON identified 2 major risk factors as predictors of fluid overload events: elevated baseline B-type natriuretic peptide and prior hospitalization for heart failure [13]. Patients without these risk factors showed no imbalance in heart failure events or mortality, which is consistent with phase 1 and 2 clinical studies that primarily enrolled patients with CKD stage 3 who had better baseline kidney function and less cardiovascular disease $[8,14]$ than BEACON participants. Clinical development of bardoxolone methyl was restarted ex- cluding at-risk patients by using these identified risk factors and closely monitoring trial participants for signs and symptoms of volume retention during the first few weeks after treatment initiation. Bardoxolone methyl is currently being tested in a global study in patients with CKD due to Alport syndrome (CARDINAL; NCT03019185), in patients with T2D and CKD in Japan (TSUBAKI; NCT02316821), a global phase 2 study of various pulmonary hypertension subtypes (LARIAT; NCT02036970), and a global phase 3 study of pulmonary arterial hypertension associated with connective tissue disease (CATALYST; NCT02657356). An interim analysis from the TSUBAKI study demonstrated that bardoxolone methyl increases GFR measured by inulin clearance after 16 weeks of study drug administration, without increasing the risk for fluid overload [11]. Additional posthoc analyses of BEACON presented here were performed to further characterize eGFR changes with bardoxolone methyl.

\section{Methods}

Clinical Study Design

Previous publications describe the BEACON trial design [10, 15]. Patients with T2D and CKD stage 4 were randomized 1:1 to once-daily administration of bardoxolone methyl $(20 \mathrm{mg})$ or placebo. The primary efficacy outcome of the study was the time-tofirst event in the composite outcome defined as end-stage renal disease (ESRD; need for chronic dialysis, renal transplantation, or renal death) or cardiovascular death. Secondary efficacy outcomes included the change in eGFR, time-to-first hospitalization for heart failure or death due to heart failure, and time-to-first event of a composite consisting of non-fatal myocardial infarction, non-fatal stroke, hospitalization for heart failure, or cardiovascular death. An independent events adjudication committee (EAC), blinded to study treatment assignment, evaluated whether ESRD events, cardiovascular events, strokes, and fatalities met pre-specified definitions of primary and secondary endpoints, as described in the EAC charter [10]. Estimated GFR was calculated using serum creatinine and the Modification of Diet in Renal Disease study equation and assessed every 4 weeks through week 12, followed by assessments every 8 weeks thereafter. The study protocol was approved by Institutional Review Boards at participating study sites and was registered at ClinicalTrials.gov (NCT01351675).

\section{Statistical Methods}

We performed longitudinal analyses of eGFR using mixed-effects regression with study group, time, the interaction of study group with time, eGFR at baseline, the interaction of baseline eGFR with time, and urinary albumin-to-creatinine ratio as covariates, and compared the mean changes in eGFR between the bardoxolone methyl and placebo groups.

We performed post-hoc time-to-event analyses for a composite renal endpoint consisting of 2 surrogate endpoints for kidney 
failure, $\geq 30 \%$ decline from baseline in eGFR or eGFR values $<15$ $\mathrm{mL} / \mathrm{min} / 1.73 \mathrm{~m}^{2}$ (for patients with baseline eGFR $\geq 15 \mathrm{~mL} /$ $\mathrm{min} / 1.73 \mathrm{~m}^{2}$ ), and adjudicated ESRD events in the intent-to-treat population in BEACON. Confirmation of each eGFR decline event was based on $\geq 30 \%$ decline from baseline in eGFR or eGFR $<15 \mathrm{~mL} / \mathrm{min} / 1.73 \mathrm{~m}^{2}$ occurring at 2 or more visits. Hazards ratios and $95 \%$ CI were computed using Cox proportional hazards regression models. Cases in which a patient had an eGFR value that declined $\geq 30 \%$ or fell below $15 \mathrm{~mL} / \mathrm{min} / 1.73 \mathrm{~m}^{2}$ at the last visit, but did not have a second confirmatory visit, were not considered events. Patients who did not experience one of these events were censored using the following conventions: patients who died from any cause prior to the end of the study were censored at the date of death; patients who discontinued the study prematurely, withdrew consent, or were lost to follow-up prior to the end of the study were censored at their last date of contact; patients who were alive and still being followed were censored on the study termination date. Similar analyses were also performed for a composite endpoint consisting of only the 2 surrogate endpoints for kidney failure $(\geq 30 \%$ decline in eGFR and eGFR $<15 \mathrm{~mL}$ / $\min / 1.73 \mathrm{~m}^{2}$ ).

\section{Results}

\section{Patients}

A total of 2,185 were randomly assigned to receive bardoxolone methyl ( $n=1,097)$ or placebo $(n=1,088)$. Previous publications detail the patient demographics and baseline characteristics of the intention-to-treat population in BEACON $[10,16]$ (online suppl. Table 1; for all online suppl.material, seewww.karger.com/doi/10.1159/000486398). The demographics and baseline characteristics for the subset of patients that remained on study through 48 weeks of treatment (bardoxolone methyl, $n=241$; placebo, $n=281$ ) were similar, but generally had lower baseline urine albumin-to-creatinine values relative to the overall intentionto-treat population (online suppl. Table 1). The median duration of exposure to the study drug was 7 months (25th-75th percentile range: $3-11$ ) among patients randomly assigned to bardoxolone methyl and 8 months (25th-75th percentile range: $5-11$ ) among those randomly assigned to placebo.

\section{Bardoxolone Methyl Increases eGFR}

As previously described, patients randomized to bardoxolone methyl had mean overall increases in eGFR of $5.5 \mathrm{~mL} / \mathrm{min} / 1.73 \mathrm{~m}^{2}$ from a mean baseline eGFR of $22.4 \pm$ $4.3 \mathrm{~mL} / \mathrm{min} / 1.73 \mathrm{~m}^{2}$. In contrast, patients randomized to placebo arm had mean baseline eGFR values of $22.5 \pm 4.6$ $\mathrm{mL} / \mathrm{min} / 1.73 \mathrm{~m}^{2}$ and experienced a mean decline in eGFR of $-0.9 \mathrm{~mL} / \mathrm{min} / 1.73 \mathrm{~m}^{2}$ corresponding to a difference between groups of $6.4 \mathrm{~mL} / \mathrm{min} / 1.73 \mathrm{~m}^{2}(p<0.001)$ [17].
The early improvements in eGFR with bardoxolone methyl were correlated with a sustained response and sustained eGFR increases; week 12 changes in eGFR were significantly correlated with changes from baseline in eGFR at week $48(r=0.48, p<0.001$; Fig. 1$)$ and 4 weeks post-drug withdrawal ( $r=0.43, p<0.001$; Fig. 1). Moreover, the increase in eGFR was highly consistent among patients, with over $75 \%$ of patients having some increase from baseline levels in eGFR at week 48 (Fig. 2). The magnitude and proportion of patients with increases in eGFR from baseline $>3 \mathrm{~mL} / \mathrm{min} / 1.73 \mathrm{~m}^{2}$ after 48 weeks of treatment was also significantly higher $(p<0.001)$ in patients treated with bardoxolone methyl (147 out of 241 [61\%]) versus placebo (41 out of 281 [15\%]).

\section{Increases in eGFR Associated with Reduced Loss of}

\section{Kidney Function}

More than twice as many patients randomized to placebo experienced a composite kidney endpoint (147 vs. 67 in patients randomized to bardoxolone methyl, hazards ratio 0.48 [95\% CI 0.36-0.64]; $p<0.0001$; Fig. 3). For the composite that did not include adjudicated ESRD events, bardoxolone methyl decreased the proportion of patients with a confirmed $30 \%$ decline in eGFR or eGFR $<15 \mathrm{~mL} / \mathrm{min} / 1.73 \mathrm{~m}^{2}$ by nearly $70 \%$ ( $n=29$ for bardoxolone methyl versus, $n=116$ for placebo; hazards ratio: 0.26 [95\% CI 0.18-0.40]; $p<0.0001$; Fig. 3). The individual components of the composite renal endpoint occurring in patients randomized to bardoxolone methyl versus placebo are shown in online supplementary Table 2.

The number of patients who experienced a renal and urinary disorder serious adverse event (as defined by the Medical Dictionary for Regulatory Activities, MedDRA version 14.0) was numerically lower in the bardoxolone methyl group than in the placebo group (52 vs. 71, respectively). Numerically fewer ESRD events were observed in the bardoxolone methyl group than in the placebo group (43 of 1,088 [4.0\%] vs. 51 of 1,097 [4.6\%], respectively) [17].

Bardoxolone Methyl Treatment Is Associated with a Sustained eGFR Increase after Withdrawal of Drug

Patients also participated in a 4-week withdrawal period following the last on-treatment visit. Based on the drug's elimination half-life of approximately $40 \mathrm{~h}$, subtherapeutic concentrations are achieved within approximately 10 days after drug withdrawal, and the 4-week withdrawal period represents approximately 17 half-lives of the drug. Moreover, there are no major metabolites with pharmacologic activity, so eGFR was assessed after
Chin et al. 


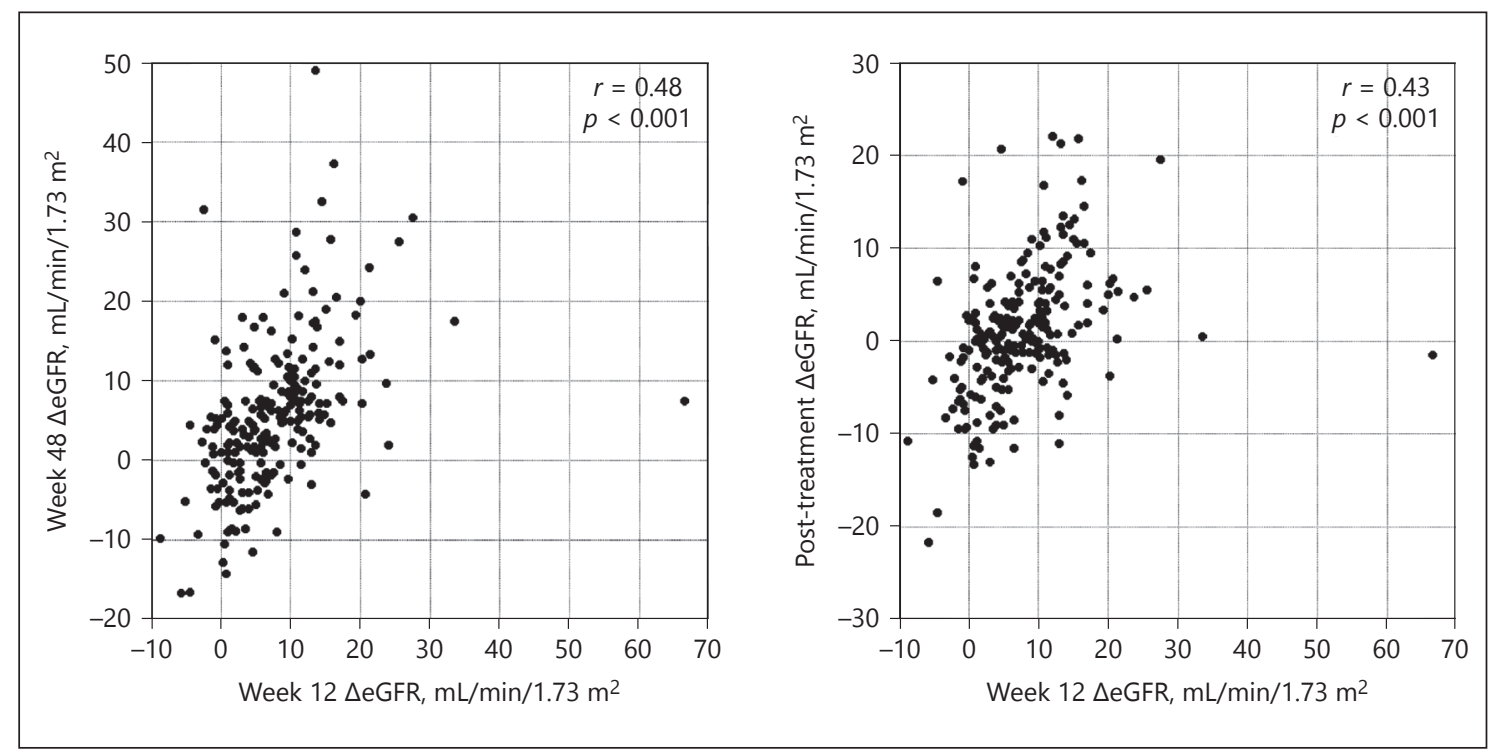

Fig. 1. Early increases in eGFR with bardoxolone methyl correlate with durable response through 1 year and sustained eGFR benefit in BEACON. Scatter plots of (left) week 12 vs. 48 changes from baseline in eGFR and (right) changes from baseline in eGFR at week 12 vs. 4 weeks after last dose in bardoxolone methyl-treated patients. Data only include bardoxolone methyl patients treated for at least 48 weeks with eGFR data at week 12 and $48(n=236)$ or week 12 and 4 weeks post treatment $(n=221)$. Pearson correlations were calculated using change from baseline in eGFR at week 12 with changes at week 48 or post treatment.

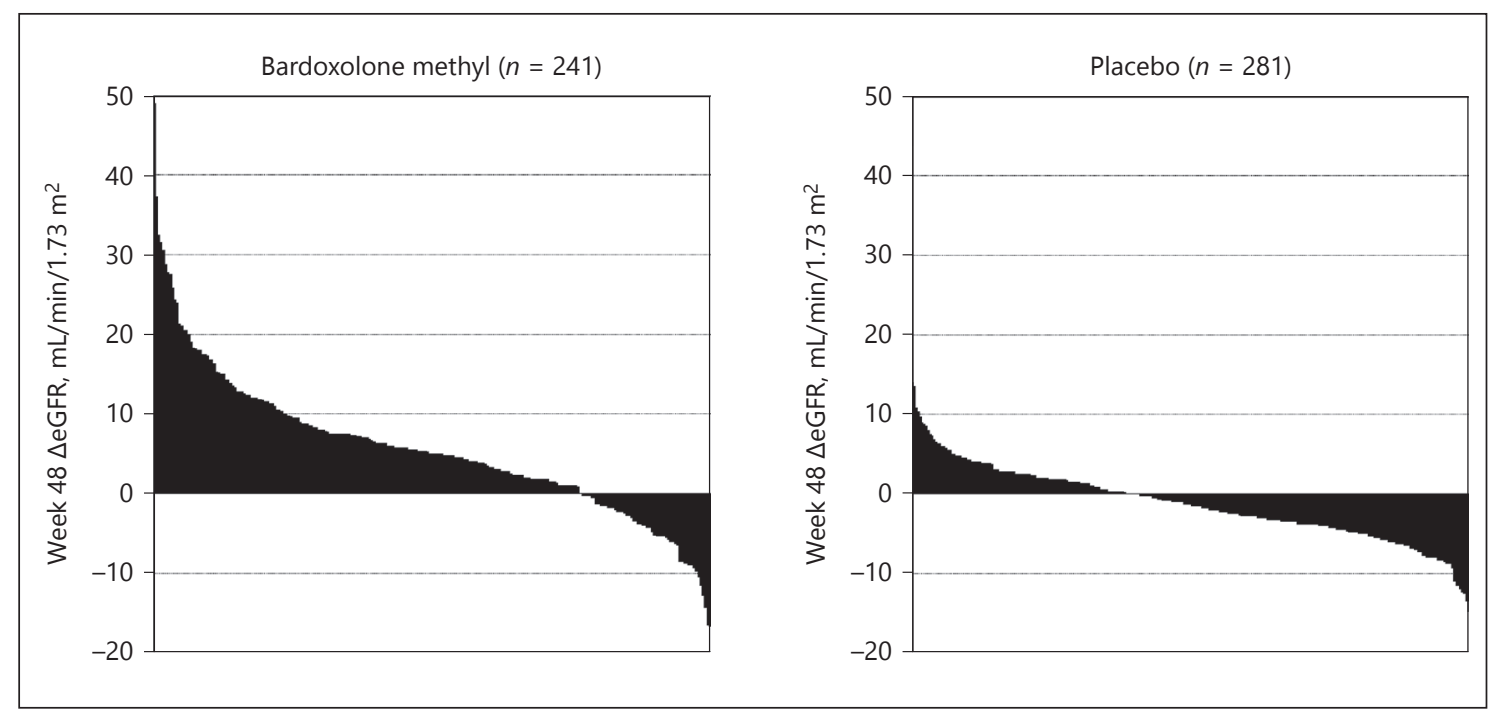

Fig. 2. Distribution of changes from baseline in eGFR at week 48 in bardoxolone methyl-treated and placebo patients in BEACON. Bars represent eGFR changes from baseline at week 48 for individual patients. Data only include patients with week 48 data.

all pharmacologic activity from bardoxolone methyl administration was lost.

Four weeks after the last dose, the mean eGFR in patients randomized to bardoxolone methyl $(n=864)$ was $24.4 \pm 8.3 \mathrm{~mL} / \mathrm{min} / 1.73 \mathrm{~m}^{2}$, which was approximately

Bardoxolone Methyl Treatment and eGFR
9\% higher than the mean baseline value of $22.4 \pm 4.3$ $\mathrm{mL} / \mathrm{min} / 1.73 \mathrm{~m}^{2}$. The mean eGFR value in patients randomized to placebo $(n=896) 4$ weeks after the withdrawal period was $22.3 \pm 6.9 \mathrm{~mL} / \mathrm{min} / 1.73 \mathrm{~m}^{2} \mathrm{com}-$ pared to a mean baseline eGFR of $22.5 \pm 4.6 \mathrm{~mL} /$ 


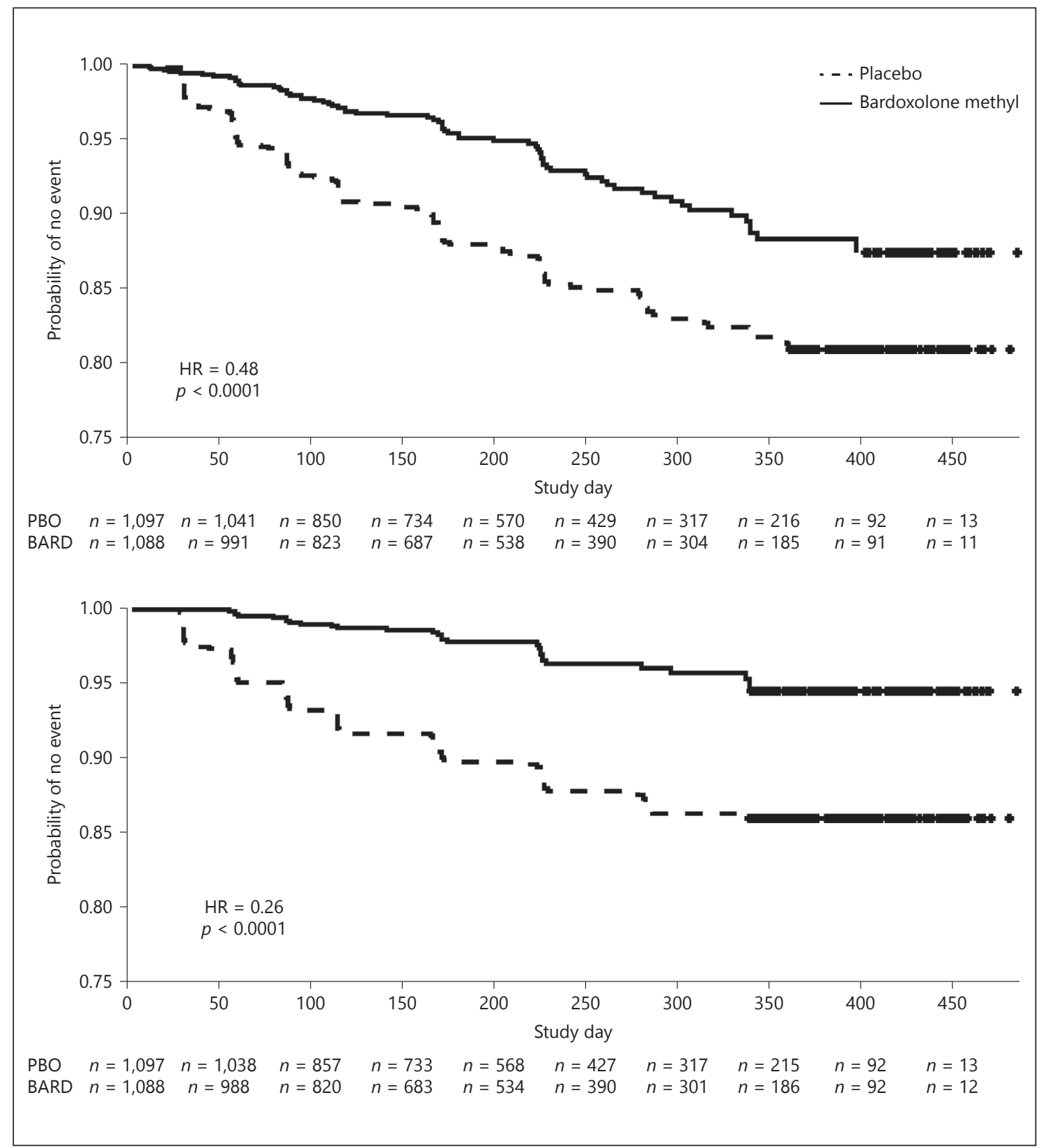

Fig. 3. Time-to-event analysis for kidney failure composite outcomes in BEACON. Kaplan-Meier plots of the time-to-first-event for composites consisting of: (top) $\geq 30 \%$ decline from baseline in eGFR, eGFR $<15 \mathrm{~mL} / \mathrm{min} / 1.73 \mathrm{~m}^{2}$, and adjudicated ESRD events; (bottom) $\geq 30 \%$ decline from baseline in eGFR and eGFR $<15 \mathrm{~mL} /$ $\mathrm{min} / 1.73 \mathrm{~m}^{2}$. Hazards ratios and $95 \% \mathrm{CI}$ were computed using Cox proportional hazards regression models. Median duration of exposure to the study drug was 7 months for patients randomized to bardoxolone methyl and 8 months for patients randomized to placebo. $\min / 1.73 \mathrm{~m}^{2}$. Similarly, for patients that received at least 48 weeks of treatment ( $n=273$ for placebo and $n=$ 225 for bardoxolone methyl), approximately $20 \%$ of the on-treatment increase in eGFR was sustained following withdrawal of therapy (Table 1). The residual eGFR in- crease from baseline observed in bardoxolone methyltreated patients $\left(1.0 \mathrm{~mL} / \mathrm{min} / 1.73 \mathrm{~m}^{2}\right)$, was significantly different from the eGFR decline from baseline observed in placebo patients $\left(-0.8 \mathrm{~mL} / \mathrm{min} / 1.73 \mathrm{~m}^{2}, p<\right.$ $0.001)$. 
Table 1. Mean eGFR change from baseline at end of treatment and 4 weeks post withdrawal in BEACON

\begin{tabular}{llcl}
\hline & \multicolumn{3}{l}{ Mean eGFR change from baseline \pm SEM } \\
\cline { 2 - 3 } & $n^{\mathrm{a}}$ & end of treatment & 4 weeks post-withdrawal \\
\hline Placebo & 273 & $-1.2 \pm 0.3$ & $-0.8 \pm 0.3$ \\
Bardoxolone methyl & 225 & $5.7 \pm 0.6^{\mathrm{b}}$ & $1.0 \pm 0.5^{\mathrm{b}}$ \\
\hline
\end{tabular}

${ }^{\text {a }}$ Number of patients receiving at least 48 weeks of treatment with 4 -week post-withdrawal data.

${ }^{\mathrm{b}} p<0.001$ vs. placebo.

\section{Discussion}

Consistent with prior studies, patients treated with bardoxolone methyl in BEACON had mean increases in eGFR that occurred by week 4 of treatment. The early improvement in eGFR with bardoxolone methyl treatment translated to a sustained response as eGFR remained above baseline through week 48 . The maintenance of eGFR increase for 1 year suggests that the effects may be durable, and patients do not develop tolerance to the drug.

In preclinical studies, bardoxolone methyl has been shown to increase GFR by increasing glomerular surface area through reduction of endothelial dysfunction, angiotensin II-induced mesangial cell contraction, and whole glomerular contraction $[6,18,19]$, and the improvements in eGFR that are evident within the first 4 weeks of bardoxolone methyl treatment in BEACON are likely due to the reversal of these dynamic inflammation-mediated processes. Moreover, the presence of a sustained eGFR improvement after withdrawal of drug suggest that the maladaptive structural deficits that contribute to declining kidney function (such as expansion of the mesangium and interstitial fibrosis) may be improved over the course of longer term treatment with bardoxolone methyl.

The prevailing hypothesis for GFR decline in the model of CKD is that hyperfiltration accelerates glomerular damage. Based on data from preclinical studies as well as clinical studies such as African American Study of Kidney Disease, a study of blood pressure targets (i.e., mean arterial pressure of $\leq 92 \mathrm{~mm} \mathrm{Hg}$ in the intensive control group and 102-107 mm Hg in the standard control group) and specific blood pressure lowering agents (i.e., ramipril, metoprolol, and amlodipine) in hypertensive kidney disease, it has been widely believed that interventions that result in higher GFR in the short term are damaging. Agents that increase eGFR through in- creases in intraglomerular pressure would be expected to cause a decline in kidney function relative to placebo due to pressure-mediated injury; in African American Study of Kidney Disease, patients with who received amlodipine had accelerated rates of eGFR decline after 6 months of treatment compared to those receiving ramipril or metoprolol [20]. Here, we show that patients treated with bardoxolone experience a sustained increase in eGFR over time and a sizeable fraction of that increase is sustained 4 weeks after the drug has been withdrawn, long after active concentrations of the drug are evident. These results are consistent with data from a separate 52 -week phase 2 study in patients with T2D and stage $3 \mathrm{~b} / 4 \mathrm{CKD}$. In that study, patients treated with bardoxolone methyl at doses similar to that studied in BEACON also showed significant increases in eGFR relative to baseline and placebo 4 weeks after withdrawal of treatment ( $4.1 \pm 1.4$ for bardoxolone methyl-treated patients versus $-0.7 \pm 1.1$ for placebo-treated patients) [8]. Also consistent with the hypothesis that the observed increases in eGFR with bardoxolone methyl treatment are not harmful was the lack of increases in other markers of kidney injury (urinary neutrophil gelatinase-associated lipocalin and $\mathrm{N}$-acetyl-beta-d-glucosaminidase) [14].

In animals, a bardoxolone methyl analog prevents fibrosis, preserves kidney function, and slows CKD progression in the 5/6 nephrectomy model of hyperfiltration-induced chronic kidney failure [3]. It is not known whether similar structural effects occur in humans; however, the aforementioned withdrawal data with bardoxolone methyl may be indicative of disease-modifying remodeling that leads to partially sustained benefit after cessation of study drug.

The BEACON trial was terminated after accrual of only approximately one-third of the planned events. As such, too few ESRD events occurred to reliably determine the drug's true effect on delaying the risk for development 
of kidney failure. Nevertheless, bardoxolone methyl treatment resulted in a decreased number of adverse kidney outcomes in BEACON, as assessed by kidney-related serious adverse events and ESRD events. Bardoxolone methyl also significantly decreased the likelihood of a composite renal endpoint consisting of adjudicated ESRD along with 2 endpoints that have recently been established as valid surrogates for progression to kidney failure in clinical trials of CKD $[20,21], \geq 30 \%$ decline in eGFR and eGFR $<15 \mathrm{~mL} / \mathrm{min} / 1.73 \mathrm{~m}^{2}$, as well as adjudicated ESRD events in BEACON.

Bardoxolone methyl has been associated with significant decreases in weight [22], which could, in theory, contribute to the observed increases in eGFR. However, in a Japanese study, bardoxolone methyl significantly increased measured GFR, as assessed by inulin clearance, in stage 3 CKD patients after 16 weeks of treatment compared to placebo [11], demonstrating that bardoxolone methyl-mediated eGFR increases are reflective of true improvements in measured GFR. Bardoxolone methyl also significantly increases creatinine clearance [10, 14], and these increases were not associated with a change in total 24-h excretion of creatinine [14], establishing that the increase in creatinine clearance is not due to a change in creatinine metabolism. Furthermore, in BEACON and prior CKD studies, bardoxolone methyl significantly reduced other retained solutes (i.e., blood urea nitrogen, uric acid, and phosphate) in inverse correlation to eGFR increases $[8,10]$, supporting that the increases in eGFR are associated with improvements in other measures of kidney function.

Although the BEACON study was terminated due to an increase in heart failure hospitalizations in the bardoxolone methyl treated group, the increase in heart failure events appeared to be due to fluid overload that occurred in patients with 2 major risk factors: elevated baseline B-type natriuretic peptide and prior hospitalization for heart failure [13]. The clinical phenotype of fluid overload and heart failure in BEACON was similar to that observed with endothelin receptor antagonists in advanced CKD patients [23], and additional post-hoc analyses suggest that through modulation of the endothelin pathway, bardoxolone methyl may pharmacologically promote acute sodium and volume retention and increase blood pressure in patients with more advanced CKD [12]. Exclusion of at-risk patients, including those with late-stage CKD, and additional risk mitigation features have been implemented in clinical programs with bardoxolone methyl and a related analog, omaveloxolone, including 7 studies that enrolled approximately
400 patients, which have not shown increased risk for fluid overload to date. Studies are continuing, in patients without identified risk factors for fluid overload, to further evaluate the potential risk-benefit profile for bardoxolone methyl and determine whether the increases in eGFR and with bardoxolone methyl offer the potential to prevent or delay kidney function decline and progression to ESRD. Bardoxolone methyl is currently being tested in a global study in patients with CKD due to $\mathrm{Al}$ port syndrome (CARDINAL; NCT03019185) and in patients with T2D and CKD in Japan (TSUBAKI; NCT02316821).

\section{Acknowledgments}

We acknowledge the supportive role of all BEACON investigators, support staff, and patients. We thank Shobhana Natarajan, $\mathrm{PhD}$., of Reata Pharmaceuticals, for assistance in preparation of the manuscript.

\section{Financial Disclosure}

Dr. Melanie P. Chin, Ms. Angie Goldsberry, Dr. Megan O'Grady, and Dr. Colin J. Meyer are employees of Reata Pharmaceuticals. Dr. George L. Bakris is a consultant for Merck, Bayer, Relypsa, and Vascular Dynamics. He is on the steering committee for clinical trials sponsored by Bayer, Janssen, and AbbVie. Dr. Geoffrey A. Block reports personal fees from KHK and is a consultant to KHK and Reata Pharmaceuticals. Dr. Glenn M. Chertow is a consultant to Reata Pharmaceuticals. Dr. Lesley A. Inker reports funding to Tufts Medical Center for research and contracts with the National Institutes of Health, National Kidney Foundation, Pharmalink AB, and Reata Pharmaceuticals. She has consulting agreements with Tricida Inc and Omeros Corp and has a provisional patent (Coresh, Inker and Levey) filed 8/15/2014 - "Precise estimation of GFR from multiple biomarkers" PCT/US2015/044567. The technology is not licensed in whole or in part to any company. Tufts Medical Center, John Hopkins University, and Metabolon Inc. have a collaboration agreement to develop a product to estimate GFR from a panel of markers. Dr. Hiddo J.L. Heerspink is consultant for and received honoraria from AbbVie, Astellas, Astra Zeneca, Boehringer Ingelheim, Fresenius, Janssen, and Merck. He has a policy that all honoraria are paid to his employer. Dr. Pablo E. Pergola reports consulting fees from Reata Pharmaceuticals during the conduct of the study; his institution, Clinical Advancement Center PLLC, receives financial support since he is a PI of multiple studies. Dr. Christoph Wanner received honoraria for consultancy and lecturing from Abbvie, Actelion, Amgen, Bayer, Boehringer-Ingelheim, GSK, Janssen, Lilly, Protalix, Sanofi-Genzyme, and Shire. Dr. David G. Warnock is an investor in Reata Pharmaceuticals, and a consultant for Reata Pharmaceuticals, Sanofi/Genzyme Corporation, Actelion Pharmaceuticals, Ltd., and Protalix Biotherapeutics.
Chin et al. 


\section{References}

1 Sporn MB, Liby KT, Yore MM, Fu L, Lopchuk JM, Gribble GW: New synthetic triterpenoids: potent agents for prevention and treatment of tissue injury caused by inflammatory and oxidative stress. J Nat Prod 2011;74:537545.

2 Ruiz S, Pergola PE, Zager RA, Vaziri ND: Targeting the transcription factor Nrf2 to ameliorate oxidative stress and inflammation in chronic kidney disease. Kidney Int 2013;83: 1029-1041.

3 Aminzadeh MA, Reisman SA, Vaziri ND, Khazaeli M, Yuan J, Meyer CJ: The synthetic triterpenoid RTA dh404 (CDDO-dhTFEA) restores $\mathrm{Nrf} 2$ activity and attenuates oxidative stress, inflammation, and fibrosis in rats with chronic kidney disease. Xenobiotica 2013;44: 570-578.

4 Aleksunes LM, Goedken MJ, Rockwell CE, Thomale J, Manautou JE, Klaassen CD: Transcriptional regulation of renal cytoprotective genes by Nrf 2 and its potential use as a therapeutic target to mitigate cisplatin-induced nephrotoxicity. J Pharmacol Exp Ther 2010; 335:2-12.

5 Wu QQ, Wang Y, Senitko M, Meyer C, Wigley WC, Ferguson DA, Grossman E, Chen J, Zhou XJ, Hartono J, Winterberg P, Chen B, Agarwal A, Lu CY: Bardoxolone Methyl (BARD) ameliorates ischemic AKI and increases expression of protective genes Nrf2, PPAR $\gamma$, and HO-1. Am J Physiol Renal Physiol 2011;300:F1180-F1192.

6 Ding Y, Stidham RD, Bumeister R, Trevino I, Winters A, Sprouse M, Ding M, Ferguson DA, Meyer CJ, Wigley WC, Ma R: The synthetic triterpenoid, RTA 405, increases the glomerular filtration rate and reduces angiotensin II-induced contraction of glomerular mesangial cells. Kidney Int 2013;83:845-854.

7 Zoja C, Corna D, Locatelli M, Corna C, Cattaneo S, Meyer C, Remuzzi G, Benigni A: Targeting Keap1-Nrf2 Pathway Ameliorates Renal Inflammation and Fibrosis in Mice with Protein-Overload Proteinuria. Poster American Society of Nephrology Meeting, 2010.

8 Pergola PE, Raskin P, Toto RD, Meyer CJ, Huff JW, Grossman EB, Krauth M, Ruiz S, Audhya P, Christ-Schmidt H, Wittes J, Warnock DG: Bardoxolone methyl and kidney function in CKD with type 2 diabetes. $\mathrm{N}$ Engl J Med 2011;365:327-336.

9 Pergola PE, Krauth M, Huff JW, Ferguson DA, Ruiz S, Meyer CJ, Warnock DG: Effect of bardoxolone methyl on kidney function in patients with T2D and Stage 3b-4 CKD. Am J Nephrol 2011;33:469-476.

10 de Zeeuw D, Akizawa T, Audhya P, Bakris GL, Chin M, Christ-Schmidt H, Goldsberry A, Houser M, Krauth M, Lambers Heerspink HJ, McMurray JJ, Meyer CJ, Parving $\mathrm{HH}, \mathrm{Re}-$ muzzi G, Toto RD, Vaziri ND, Wanner C, Wittes J, Wrolstad D, Chertow GM: Bardoxolone methyl in type 2 diabetes and stage 4 chronic kidney disease. N Engl J Med 2013; 369:2492-2503.

11 KHK Press Release, 2017.

12 Chin MP, Reisman SA, Bakris GL, O'Grady M, Linde PG, McCullough PA, Packham D, Vaziri ND, Ward KW, Warnock DG, Meyer CJ: Mechanisms contributing to adverse cardiovascular events in patients with type 2 diabetes mellitus and stage 4 chronic kidney disease treated with bardoxolone methyl. Am J Nephrol 2014;39:499-508.

13 Chin MP, Wrolstad D, Bakris GL, Chertow GM, de Zeeuw D, Goldsberry A, Linde PG, McCullough PA, McMurray JJ, Wittes J, Meyer CJ: Risk factors for heart failure in patients with type 2 diabetes mellitus and stage 4 chronic kidney disease treated with bardoxolone methyl. J Card Fail 2014;20:953-958.

14 Pergola P, Krauth M, Huff JW, Ferguson DA, Ruiz S, Meyer CJ, Warnock DG: Effect of Bardoxolone on Kidney Function in Patients with T2D and Stage 3b - 4 CKD. Am J Nephrol 2011;33:469-476.

15 de Zeeuw D, Akizawa T, Agarwal R, Audhya P, Bakris GL, Chin M, Krauth M, Lambers Heerspink HJ, Meyer CJ, McMurray JJ, Parving $\mathrm{HH}$, Pergola PE, Remuzzi G, Toto RD, Vaziri ND, Wanner C, Warnock DG, Wittes J, Chertow GM: Rationale and trial design of Bardoxolone Methyl Evaluation in Patients with Chronic Kidney Disease and Type 2 Diabetes: the Occurrence of Renal Events (BEACON). Am J Nephrol 2013;37:212-222.

16 Lambers Heerspink HJ, Chertow GM, Akizawa T, Audhya P, Bakris GL, Goldsberry A, Krauth M, Linde P, McMurray JJ, Meyer CJ,
Parving HH, Remuzzi G, Christ-Schmidt H, Toto RD, Vaziri ND, Wanner C, Wittes J, Wrolstad D, de Zeeuw D: Baseline characteristics in the Bardoxolone methyl Evaluation in patients with Chronic kidney disease and type 2 diabetes mellitus: the Occurrence of renal events (BEACON) trial. Nephrol Dial Transplant 2013;28:2841-2850.

17 de Zeeuw D, Akizawa T, Audhya P, Bakris GL, Chin M, Christ-Schmidt H, Goldsberry A, Houser M, Krauth M, Lambers Heerspink HJ, McMurray JJ, Meyer CJ, Parving HH, Remuzzi G, Toto RD, Vaziri ND, Wanner C, Wittes J, Wrolstad D, Chertow GM: Bardoxolone methyl in type 2 diabetes and stage 4 chronic kidney disease. N Engl J Med 2013; 369:2492-2503.

18 Aminzadeh MA, Reisman SA, Vaziri ND, Shelkovnikov S, Farzaneh SH, Khazaeli M, Meyer CJ: The synthetic triterpenoid RTA dh404(CDDO-dhTFEA) restores endothelial function impaired by reduced Nrf2 activity in chronic kidney disease. Redox Biol 2013;1:527-531.

19 Ferguson DA, Wigley WC, Heiss E: Bardoxolone Methyl (BARD) Improves Markers of Endothelial Function in Cultured Cells. Poster American Society of Nephrology (ASN), 2010.

20 Inker LA, Lambers Heerspink HJ, Mondal H, Schmid CH, Tighiouart H, Noubary F, Coresh J, Greene T, Levey AS: GFR decline as an alternative end point to kidney failure in clinical trials: a meta-analysis of treatment effects from 37 randomized trials. Am J Kidney Dis 2014;64:848-859.

21 Levey AS, Inker LA, Matsushita K, Greene T, Willis K, Lewis E, de Zeeuw D, Cheung AK, Coresh J: GFR decline as an end point for clinical trials in CKD: a scientific workshop sponsored by the National Kidney Foundation and the US Food and Drug Administration. Am J Kidney Dis 2014;64:821-835.

22 Pergola P, Chin M, Goldsberry A, Hebbar S, Meyer C, Audhya P: Weight Loss in Stage 3b and 4 CKD Patients with Type 2 Diabetes given Bardoxolone Methyl. Paris, Presentation ERA-EDTA Meeting, 2012.

23 Mann JF, Green D, Jamerson K, Ruilope LM, Kuranoff SJ, Littke T, Viberti G: Avosentan for overt diabetic nephropathy. J Am Soc Nephrol 2010;21:527-535. 